\title{
The Path of College Students' Mental Health Education Under the New Media
}

\author{
Ping Wang 1

\begin{abstract}
'Jiangxi Vocational Technical College Of Industry \& Trade, Jiangxi, Nanchang, 330038 739960103@qq.com
\end{abstract}

\begin{abstract}
At present, with the rapid development of new media technology in China, the network information environment has been greatly improved. College students can quickly and conveniently search and obtain the information resources they need. The arrival of the new media era has a great impact on the psychology of college students. This paper starts from the positive and negative effects of the current college students' mental health education in the new media era, puts forward the existing problems of College Students' mental health education, and puts forward the targeted solutions, so as to improve the quality of College Students' mental health education, promote the development of College Students' mental health, enhance the comprehensive ability of college students, and cultivate excellent talents.
\end{abstract}

Keywords: new media era background, college students, mental health education

\section{新媒体背景下高校大学生心理健康教育的路径探究}

\begin{abstract}
王萍 1
${ }^{1}$ 江西工业贸易职业技术学院 江西 南昌 330103

739960103@qq.com

摘要:

目前，我国新媒体技术高速发展，网络信息环境得到很大的改善，高校大学生可以快速便捷地搜索 并获取需要的信息资源, 新媒体时代的到来给大学生的心理带来较大的影响。本文从当前高校大学 生心理健康教育受新媒体时代的正反面影响出发, 提出大学生心理健康教育存在的问题, 并对此提 出针对性的解决方案, 以提高大学生心理健康教育质量, 促进大学生心理健康发展, 提升大学生的 综合能力，培养优秀人才。
\end{abstract}

关键词：新媒体时代背景；大学生；心理健康教育

\section{1.引言}

新媒体时代到来, 大学生成为最受益的主要群体, 大学生在学习、生活过程中会经常使用现代多媒体应 用, 在相关信息平台上获取自己需要的数据资料、学 习资源。但是, 新媒体时代下的信息良莠不齐, 大学 生思想尚不成熟, 心智还在发育阶段, 很难在纷繁复 杂、眼花缭乱的信息中辨别、选择对自己有益的信息, 阅历尚浅、仍处于象牙塔的大学生容易受到不良信息 的迷惑, 导致自己受到心理上无法弥补的创伤。因此, 在新媒体时代下, 高校要重视对大学生正确使用新媒
体应用的教育, 开展有效的心理健康教育, 为大学生 正确价值观念和健康心理的形成创造良好条件。

2.新媒体时代对高校大学生心理健康教育的 影响

2.1 新媒体对高校大学生心理健康的正面影响

\subsection{1 新媒体促进大学生增长见识}

新媒体平台充满了各种各样、五花八门的数据信 
息，这些数据信息具有易传播、易下载、易分享等特 点, 极大便利了高校大学生获取需要的相关信息资源。 而高校大学生对世界存在的各类新鲜事物充满好奇, 具有较强的求知欲、探索欲。新媒体时代满足了大学 生足不出户看遍世界的需求, 激发大学生的学习兴趣, 提高大学生的眼界, 增长大学生的见识。

\subsection{2 新媒体满足大学生广泛社交的需求}

新媒体时代为大学生的人际交往提供了巨大的 平台, 在新媒体平台上, 大学生可以自由、平等地与 其他人沟通、交流, 分享有趣的信息。在多媒体时代, 大学生通过网络平台可以找到志同道合的好友互相 交流、分享经验、相互学习。社会交际是高校大学生 生活不可缺失的重要部分, 新媒体平台挣脱传统的空 间、时间束缚, 大学生可以和远在千里的陌生人交朋 友, 极大的拓宽了社交氛围。当然, 多媒体平台是高 校大学生情绪的宣泄处, 是大学生心灵的避风港, 大 学生会将在现实中不方便倾诉的事情和宣泄的情绪 在多媒体平台上释放出来, 以让自己减小压力, 调整 心态，平复情绪。

\subsection{3 新媒体提升大学生的综合能力}

新媒体网络除对学生的正面影响, 除了新媒体网 络可以促进大学生增长见识以及满足大学生广泛的 社交需求外, 还可以提升大学生的中和能力。新媒体 网络技术有利于创新大学生的思维模式、表达方式和 行为方式, 大量的数据信息促进大学生在思想方面、 创新方面、表达方面和行为方面的良性改变。丰富的 多媒体信息拓宽了大学生的视野, 有助于使大学生学 会深入思考、学会交流、学会表达、学会创新, 在实 际生活中运用在互联网所学知识实现具体的目标, 不 断在摸索中成长。所以, 多媒体有利于提升大学生全 面发展。

\section{2 新媒体对高校大学生心理健康的负面影响}

新媒体时代下的信息资源较为丰富, 但各种信息 的质量差异较大, 多媒体平台的信息良莠不齐, 鱼龙 混杂。高校大学生正处于世界观、人生观、价值观形 成的关键阶段, 身心发展尚未成熟, 大学生很难辨识 多媒体平台上迷惑的劣质信息, 也难以抵制不良信息 的诱惑, 不利于大学生树立正确的世界观、人生观和 价值观。据相关调查研究表明, 众多大学生沉溺于多 媒体平台的网络游戏中，而其中也包括充满了暴力、 色情等不良因素的大型网络游戏。大学生陷入游戏之 中无法自拔, 严重影响了大学生正常的生活作息、学 业活动和人际交往, 导致其形成内向、孤僻的性格, 不善于沟通交流, 不喜欢与他人交朋友, 整日活在自 己的游戏世界里, 产生十分严重的心理问题。另外, 由于部分大学生在网络游戏上花费大量的时间与精 力, 导致他们在参加相关的学习课程过程中没有足够 的积极性和求知欲, 学习效果较差, 成绩难以提高。

\section{3.新媒体时代高校大学生心理健康教育存在 的问题}

\section{1 对心理健康教育的重视不够}

据相关调查研究表明, 部分高校教学工作者没有 正确地意识到心理健康教育对高校大学生的重要性, 对高校大学生心理健康教育的认识不足, 在相关的教 育工作上没有足够的重视, 不利于高校大学生心理健 康教育质量的提高。部分高校将所有的教学重心放专 业学科上, 忽视心理健康教育对大学生的重要作用。 部分高校的心理健康教育工作者的思想观念较为传 统守旧, 教学模式单一, 专业知识落后, 没有与时俱 进, 缺乏对大学生存在各类心理问题的正确引导方法, 没有很好的将心理健康教育教学与新媒体有机结合, 导致高校大学生心理健康教育质量难以提高。

\section{2 心理健康教育师资力量不足}

目前，我国专业的心理健康教育师资力量不足， 高校有待建设专业化、高水平的心理健康师资人才队 伍。大部分高校的心理健康教师由辅导员、思想政治 教师、心理咨询室工作者兼职，非专业的心理健康教 师难以发挥心理健康教育的作用效果。

\section{3 心理健康教育的教学模式单一}

高校大学生心理健康教育采用的教学模式较为 传统、单一, 大学生难以对枯燥的心理健康课堂教学 产生学习兴趣。虽然高校大学生极度关注多媒体, 但 目前的心理健康教育模式没有与多媒体有机结合, 对 网络等多媒体手段应用较少, 所以大学生参与心理健 康课堂教学的积极性、主动性也难以提高。

\section{4 心理咨询室不够完善}

新媒体时代下, 高校针对大学生的心理健康教育 问题，除了上述三点以外，还有心理咨询室不完善的 问题。据调查研究表明, 大部分高校没有建设专门的 心理健康教育机构, 其心理教育的任务工作也分配给 各学院辅导员进行。部分高校的心理健康教育经费不 足, 相关的心理咨询室、心理教育设备不够完善, 难 以发挥心理健康教育的作用，可见高校心理健康教育 的发展水平不高, 难以满足大学生心理健康发展的需 要。

\section{4.新媒体时代高校大学生心理健康教育路径}

\section{1 优化环境, 为高校大学生心理健康教育创造 良好的氛围}

高校要积极营造良好的心理健康教育环境, 创造 良好的精神文化氛围。学校可以积极开展校园文化活 动, 为广大高校学生普及心理学的基础知识。教师在 
心理健康教育的课堂教学上要注重把学生心理健康 教育的要求、内容以及目的渗透到心理教学活动中, 通过有形载体, 引导高校大学生的精神和心理朝着文 明和健康、高雅的方向努力。高校要重视心理健康教 育的必要性, 同时也要提高学生对心理健康教育重要 性的认识, 激发学生学习的动力, 帮助学生增强自身 防御心理疾患的意识和能力。另外, 网络管理相关部 门也要承担相应的社会责任, 为社会打造良好的、健 康的网络环境。

\section{2 专业学科教学与心理健康教育有机结合}

各高校要积极将心理健康教育渗透到高校各专 业教学环节。在各专业教学过程中, 专业教师要将心 理健康教育的相关内容与专业知识有机结合, 在为学 生传授专业知识和技能的同时也为学生进行心理健 康教育的辅导。专业教师可以将心理健康教育相关知 识与专业教学课件相结合, 高校大学生在学习专业知 识的同时也能自主学习心理健康教育知识。在思想政 治课堂教学过程中, 政治老师要提高大学生对心理健 康教育重要性的认识, 引导大学生正确的。调整心态, 解决心理问题。另外，政治老师也可以帮助心理问题 较为严重的学生, 引导大学生提升心理健康自我调节 的能力。

\section{3 实现大学生心理健康教育方式多元化}

单一、枯燥的大学生心理健康教育方式难以满足 大学生的心理需求, 高校要努力实现大学生心理健康 教育方式多元化, 综合运用多媒体的网络技术, 创新 心理健康教育模式, 丰富心理健康教育的教学内容, 采用线上线下相结合的教学形式, 针对性地为高校大 学生开展相关的心理健康教育活动。譬如对于众多高 校大学生沉溺网络游戏的问题, 高校可以开展以“防 止沉迷游戏”主题的心理健康教育讲座。

\section{4 引导大学生心理健康自我调节}

高校大学生心理健康教育最重要的目的是实现 大学生具有自我心理调节的能力。自我调节心理健康 的核心内容包括: (1)改善适应能力(2)调整情绪状态(3) 锻炼意志品质(4)调整认识结构。高校需要为大学生打 造自我调节、自我磨砺、自我教育的心理健康教育氛 围, 积极引导大学生利用学校给予的有利条件实现心 理健康自我调节能力的提升。高校要通过新媒体技术 为高校大学生分享丰富的心理健康教育资源, 如电子 类书籍刊物、网络课程和纸质书籍等, 引导高校大学 生自主学习心理健康教育的相关网络课程, 自主阅读 心理健康教育书籍, 提高高校大学生预防自身心理健 康问题的能力, 并引导高校大学生掌握解决自身心理 健康问题的方法。

\section{5 搭建高校大学生心理健康教育网络平台, 构建三维立体心理健康教育阵地}

目前, 我国高校大学生使用的社交平台主要为 $\mathrm{QQ}$ 、微信和微博。高校可以结合新媒体技术为大学生 搭建高校大学生心理健康教育网络平台, 构建三维立 体心理健康教育阵地。为大学生解决心理问题提供便 利途径。线上心理咨询平台的建立避免了高校大学生 去实体的心理咨询室容易产生的难为情、筳尤等负面 情绪的问题, 更好地保护高校大学生的隐私, 线上心 理咨询平台更容易为大学生所接受。因此, 高校可以 建立 QQ 心理咨询平台、微博心理咨询平台、微信公 众号心理咨询平台等, 这些线上心理咨询平台为解决 高校大学生的心理问题服务, 帮助学生正确的看待自 己的心理问题, 实现心态自我调节, 增强学生的心理 素质，最后解决心理问题。

\section{6 更新心理健康教育内容，改变教育方式方 法、利用新媒体平台开展课堂教学模式}

高校大学生心理健康教育要引导学生身心朝着 积极、向上、健康、乐观的方向发展。高校要努力提 高心理健康教育的教学质量, 增强大学生对心理健康 教育新型模式的适应性、主动参与性。高校可以综合 运用多种新媒体技术手段构建心理健康教育主题的 线上平台，平台设置相关心理教育主题的交流栏目， 高校利用新媒体平台开展课堂教学模式, 增加心理健 康教育工作者与学生之间的互动, 一方面有利于心理 健康教育者对学生心理健康动态的把握, 另一方面, 有利于学生正确地认识自己的心理问题, 掌握预防和 解决心理问题的有效方法, 促进学生的身心健康发展。

\section{5.结论:}

新媒体时代下，飞速发展的网络信息技术使高校 大学生心理健康受到较大影响, 众多高校大学生心理 健康教育存在诸多问题, 高校作为大学生心理健康教 育的主要阵地, 要勇于革新心理健康教育模式, 更新 心理健康教育内容, 改变教育方式方法, 利用新媒体 平台开展课堂教学模式, 搭建高校大学生心理健康教 育网络平台, 构建三维立体心理健康教育阵地, 为高 校大学生心理健康教育创造良好的氛围, 有利于提高 大学生心理健康自我调节的能力, 增强大学生的良好 心理素质, 使大学生拥有健康的身心, 促进其成人、 成才、成功。

\section{REFERENCES}

[1] Yao Yangang, Li Wancheng, Wu Shanshan, Huang Weili. Exploration on the working mode of mental health education for college students in the new era -- Taking "warm Friday" studio of Life Science College of Hefei Normal University as an 
example [J]. Journal of Kaifeng Institute of education, 2018,38 (6): 160-161

[2] Sun Jiangjie, Zhang Liping, Xie Fangzhou, he Chengsen. A new model of mental health education in Colleges and Universities under the Internet environment [J]. Journal of Nanjing Medical University: Social Science Edition, 2015,0 (5): 399-402

[3] Cruss, R.L., cruss, S.R., Steinert, Y., cultivation of medical professionalism [M]. Peking University Medical Press, 2013

[4] Li Hongmei talks about the new mode of mental health education in Colleges and Universities under the Internet environment $[\mathrm{J}]$, Journal of Liaoning Teachers College: Social Science Edition, 2016,0 (5): 100-101

[5] Sun Jiangjie, Zhang Liping, Xie Fangzhou, Yang Ping, Ma Nanzhen, he Chengsen. Study on the model of doctor-patient risk management and control from the perspective of medical professionalism []. Journal of Huaihua University, 2016,35 (4): $62-65$

[6] Sun Jiangjie, Zhang Liping, Yang you, Xia Yun, mu pengkun, Ma Nanzhen, Li Xiaosong, he Chengsen. Survey on the evaluation of College Students' mental health education [] Journal of Jinzhou Medical University: Social Science Edition, 2017,15 (2): 58-61

[7], Niu Hongyu, a new way of network mental health education in the new media era. Take the construction of WeChat official account as an example [modern business and trade industry, 2017,38 (19): 154-155.

[8] Ma Hongxia, Liu Xiaoling, Gao Yuechun, Chen Xin, Niu Chunjuan. Reform and practice of "Trinity" teaching mode of College Students' Mental Health Education -- taking pressure management and frustration response as an example [J]. Journal of North China University of Technology: Social Science Edition, 2018,18 (1): 86-89

[9] Sun Jiangjie, Zhang Liping, Xie Fangzhou, he Chengsen. A new model of mental health education in Colleges and Universities under the Internet environment [J]. Journal of Nanjing Medical University: Social Science Edition, 2015,0 (5): 399-402

[10] Xu Jing, Li Xiaolu, Su Qingyuan, Zhang zhehao. Exploration and practice of Internet mental health education for College Students -- Taking School of chemical engineering, Yan'an University as an example $[\mathrm{J}]$. Education and teaching forum, 2020,0 (16): 88-90

[11] Liu Yanling, pan yangu, Tang Ling. Construction of College Students' mental health education curriculum system based on psychological quality training [J]. Journal of Southwest University: Social Science Edition, 2014,40 (3): 93-97

[12] Zhu Zhanzhan. On the teaching reform of intelligence and mental health in Higher Vocational General Education -- Taking Hunan Mass Media Vocational and Technical College as an example [J]. Journal of Hunan Mass Media Vocational and technical college, 2015,15 (1): 111-114

[13] Luo Fusheng, Shen Dan, Zhang Shanming, Wang Xiaofeng, Yuan Hongmei, Li Zhiqiang. Mental health status of impoverished college students and its influencing factors $[\mathrm{J}]$. Chinese Journal of clinical psychology, 2009 (3): 272-274

[14] Zhang Dajun, Li Xiaohui, Gong Ling. Theoretical thinking on psychological quality and its formation mechanism (1) -- Discussion Based on the theory of cultural and historical activities [J]. Journal of Southwest University: Social Science Edition, 2013 (2): 71-76

[15] Yu Guoliang. Research on social mentality and mental health service from the perspective of social transformation (special discussion) -Social Transformation: mental health service and social psychological service [J]. Heilongjiang Social Sciences, 2018,0 (4): 62-69

[16] Sun Zhuo. Characteristics and Countermeasures of College Students' psychological problems -Based on the analysis of 242 college students' psychological consultation records [J]. Journal of Zhoukou Normal University, 2018,35 (5): 143146

[17] Journal of Liaoning Medical College: Social Science Edition, 2016,14 (4): 88-91 